\title{
TESTS FOR PHYSICAL LAWS OF DRAFT FORCE GENERATED IN TILLAGE OPERATIONS
}

\author{
Petru Cardei, Paula Condruz, Raluca Sfiru, Cornelia Muraru \\ National Institute of Research-Development for Machines and Installations \\ Designed to Agriculture and Food Industry, Romania \\ petru_cardei@yahoo.com,paula.condruz91@gmail.com,raluca_sfiru@yahoo.com, \\ cornelia.muraru@gmail.com
}

\begin{abstract}
The article presents results of the testing of some physical laws of the phenomenon of interaction between soil and the working parts of agricultural machines destined to the soil tillage. The authors try, gradually, to clarify the quality of the approximation of the tillage draft forces of the tillage machines, offered by the multitude of mathematical models and their variants from the literature. The presented material reflects the situation that the authors consider to be characterized, apparently, by heterogeneity regarding the use of formulas for the draft soil tillage force. In essence, a disputed response between the practical and didactic utility is outlined, that is simple formulas (which are very particular, because they take into account few parameters of the phenomenon) that approximate very well the experimental values, vs. complex formulas, with a large number of parameters that characterize (explain) the phenomenon well, but which require a large number of data for application and have lower accuracy than simple formulas. A third way, also with great age, namely, that of statistical interpolation formulas, with high accuracy, but small generality, based on concrete experiences (which are difficult to generalize) and which often do not fully satisfy dimensionality requirements (for the physical correctitude). It is presented in the paper.
\end{abstract}

Keywords: tillage, draft, formulae, tests.

\section{Introduction}

In the literature dedicated to the problem of finding a formula of the force of resistance generated by the machines intended for soil tillage, it is noted in over 100 years of scientific production, certain crystallizations around some basic components, such as, for example, the force component dependent on the second power of the working speed. In the last fifty years, there have also been trends that promote statistical formulas, coming from the ordinary interpolation of experimental data. The dependences on the speed of work, the depth and the working width, in general, can be found in the formulas from both categories. The difference lies in the physical significance of the coefficients and in the dimensional correctness of the arguments of the transcendental functions. This paper aims to highlight the common components of the formulas in the accessible speciality literature and to draw some conclusions regarding their physical significance, especially referring to the dimensional aspect. The beginning of the investigations in this problem is outlined in [1]. However, the basic problem of this paper is to show the extent, to which the examined physical laws correctly model experimental data obtained in the current research activity. The term correctness is defined by the method of deciding whether a formula (a physical law) is physically acceptable and is based on dimensional correctness and normal values of the model parameters that define them. These criteria are explicitly given in the method description. They represent the authors' conviction and do not represent a mandatory requirement in scientific activity.

The bases of the construction of such formulas are generally different, depending on the nature of the scope. From an agricultural point of view, the interest in the construction of such formulas is illustrated in [2-11] for example.

Formulas starting from the point of view of specialists in the field of civil constructions or machines used in construction or mining, but also in agriculture, and which regard the soil as being mathematically modelled as a continuous body, appear in $[12 ; 13]$, e.g. We should also mention the fact that in this study we work with the longitudinal component of the draft soil tillage force, that is, the reasoning of the work does not include the vertical and lateral components of this force. The material presented in this article considers that all the experimental results are correct and all the mathematical models pretending to the title of the law of the draft soil tillage force are approximations of the reality. The authors propose only a way of selecting the mathematical models proposed, by virtue of principles that seem reasonable to them. 


\section{Materials and methods}

The material that is subjected to the research in this paper is composed of a lot of formulas (mathematical models) of the draft force, generated by the interaction between the soil and the agricultural machines intended for soil tillage. The phenomenon described by this law is common in the fields of agricultural machines and machines intended for mining or land management, civil construction, etc. The broad spectrum of use of mathematical models of the force of interaction between the machine and the ground determines, to a certain extent, the structure as a set of mathematical relations, of what we call the law of the force of interaction between the ground and the working parts of a machine in interaction with the ground. These formulas give the force of resistance, which is opposed to the machines that interact with the ground (the effect), depending on a series of parameters of the phenomenon (the causes).

The fact that there are several formulas proposed for the soil tillage draft force, even for the same machine, with the same working parts, could lead to a simplistic conclusion: more truths mean no truth. However, the reality is more complex in the vast majority of the formulas converge both qualitatively (in the sense of the main group of parameters that influence the phenomenon) and quantitatively, giving comparable values for the draft soil tillage force, under similar or sensibly close conditions. The multitude of variants existing for this physical law is due also to a large number of factors (parameters) with a great influence on the draft soil tillage force: soil structure and composition factors (inhomogeneous and non - isotropic environment), environmental factors (especially the soil moisture), geometry of the working bodies involved in the process, parameters of the working regime (working speed), energetic parameters that also include the geometry of the processed terrain, interaction of the towing machine with the soil, characteristics of the turns, etc. Each of these partial laws is true (in the sense of a good approximation) in a very particular case, in which the parameters that are not taken into account and are considered specified constants. These variants reduced by the number of parameters are very precise, but unnecessary, or not true in the general case or in a case, where it is applied for values of the fixed parameters, different from those used in the experiments performed for deduction of the law. On the other hand, the physical laws for the draft soil tillage force, which take into account a large number of influential parameters, achieve, in most particular cases, a lower accuracy than the particular laws formulated for the same phenomenon. The formulas of the draft soil tillage force that highlight the most influencing parameters are those of type [1], those given in [3], or those of the researches that used dimensional analysis to determine it, for example [14]. Therefore, the material we deal with in this test is a physical law in a development stage, in which partial variants try to acquire a convergent character, in order to set out a complex form, which should include as many parameters, which influence the phenomenon. Obviously, the desire to obtain a complete theory of the phenomenon is, for the time being, an ideal and, probably, it will remain so. However, mathematical models that materialize this physical law and can provide useful data in designing and operating machines that interact with the soil exist and can be refined to identify improved or even optimal working regimes. The general method of testing the formulas for the traction force required for the machines intended for soil works is based on the existence of a clear formula and a sufficiently large batch of experimental data, in order to be able to identify the model constants, using the method of the smallest squares. This method is well known in the field of system parameter identification.

The criteria of acceptance of the physical laws will be:

- C1-formulas must have a physical meaning, in the sense of dimensional correctness;

- $\mathrm{C} 2$-in the additive composition of the formulas, generally negative terms will not be accepted, because the negative components would have the meaning components that lead to the decrease of the tillage draft force.

The criterion $\mathrm{C} 1$ is reflected in the physical dimension of the model parameters and their physical unit (see Table 1). The criterion $\mathrm{C} 2$ will generally be supplemented with mentioning that the values of the model parameters must be included in the ranges of values that include sufficiently tightly the intervals specified by the literature, if the respective data are available. For the laws of physics are required certain characteristics, which, at least in this phase of the construction of the law of draft tillage force, are very restrictive. 
In essence, the paper presents a method of selecting formulas for the law for calculating the draft force of the agricultural machinery for soil tillage. This method has two main components. The first component selects the proposed formulas according to the physical dimensional correctness. The second criterion, calculating the parameters of the proposed formulas by statistical interpolation methods, evaluates the statistical performances of the formulas and the accuracy of the experimental data. In this way, a hierarchy of the proposed formulas can be given for each batch of the experimental data considered. Three batches of experimental data were used to present the experimental data in this paper. Two types of formulas, with variants, were tested for example. Additional information and data can be found in [15].

\section{Results and discussion}

The results presented in this chapter refer to the tests performed for some known formulas using experimental data from the specialized literature. The physical significance and the units of measurement of the parameters involved in the formulas discussed in this paper are given in Table 1.

Parameters of the interaction process between soil and the soil tillage machinery: notations, significance and units of measure

\begin{tabular}{|c|c|c|}
\hline Notation & Name & Unit \\
\hline$F$ & Draft force & $\mathrm{N}$ \\
\hline$A$ & Static coefficient of term of the draft force & $\mathrm{N}$ \\
\hline$B$ & Coefficient of the term that depends on the working speed of the draft force & $\mathrm{kg} \cdot \mathrm{s}^{-1}$ \\
\hline$C$ & Coefficient of the term that depends on the square of the working speed & $\mathrm{kg} \cdot \mathrm{m}^{-1}$ \\
\hline$\varphi$ & Dimensionless factor of soil texture: $\varphi=1$ fine,$\varphi=2$ average, and $\varphi=3$ coarse & - \\
\hline$v$ & Working speed & $\mathrm{m} \cdot \mathrm{s}^{-1}$ \\
\hline$b$ & Working body width & $\mathrm{m}$ \\
\hline$a$ & Working depth & $\mathrm{m}$ \\
\hline$k$ & Coefficient that characterizes specific soil deformation resistance & $\mathrm{MPa}$ \\
\hline$\varepsilon$ & Coefficient depending on the shape of the active surface of the body and the soil & $\mathrm{kg} \cdot \mathrm{m}^{-3}$ \\
\hline$f$ & properties & - \\
\hline$G$ & Gravitational acceleration & $\mathrm{N}$ \\
\hline$g$ & Soil mass density & $\mathrm{m} \cdot \mathrm{s}^{-2}$ \\
\hline$\rho$ & Horizontal blade angle (rake angle) & $\mathrm{kg} \cdot \mathrm{m}^{-3}$ \\
\hline$\alpha$ & Number of working bodies & $\mathrm{rad}$ \\
\hline$n$ & Lateral displacement angle of the furrow & - \\
\hline$\varphi_{s}$ & Coulter sharpening angle & $\mathrm{rad}$ \\
\hline$\delta$ & Degree of dislocation of the soil & $\mathrm{rad}$ \\
\hline$G_{A}$ & Plough weight & - \\
\hline
\end{tabular}

The first tests, which results are given below, are done for Goriacikin's formula, [2]:

$$
F=f G+k a b n+\varepsilon a b v^{2} n
$$

The formula is tested for the experimental data from [16-18]. It can be observed that in the mathematical formula or model of the tillage draft force, there are control and command parameters (known exactly or less exactly) related to the physical and geometrical characteristics of the machine, $G, a, b, n, v$, and the model parameters $(f, k, \varepsilon)$. The exact control of the parameters refers to $G$ and $n$, and a statistically satisfactory experimental control admits the parameters $a, b, v$. The test method of formula (1) will be explicit only for the experimental data in [16], for the other experimental data sets presenting only the synthetic results in the form of tables. The authors [16] give a number $N=24$ experimental data in graphic form, which was obtained for a winged share with leading chisel working body, with the main characteristics given in [16]. The experiments are done in laboratory conditions, on soil with known characteristics. By taking the data from the graphical representation from [16], within the precision limits of the reading, and applying the method of the smallest squares, the following values for the model parameter combinations are obtained: 


$$
f G=-1013.475 \mathrm{~N}, k=29420.296 \mathrm{~N} \cdot \mathrm{m}^{-2}, \varepsilon=169 \mathrm{~kg} \cdot \mathrm{m}^{-3} .
$$

As the friction force, $f G$ is negative, it follows that formula (1) does not correctly model the experimental data from [16]. The coefficient $k$ takes a value that falls within the range indicated in most of the literature promoting this formula, [2], [4-8]. Although positive, the value of the coefficient $\varepsilon$, determined by the method of the smallest squares in the experimental data from [16], is not in the range indicated by [2] or [4-8]. The interpolation of the experimental data from [16], leads to a correlation between the experimental and the interpolation data with the value 0.983 and a regression coefficient with the value 0.966 . Therefore, as the pure interpolation method, the method used is satisfactory. However, according to the criteria of correctness adopted, the conclusion is that Goriacikin's formula (1) does not correctly model the experimental data from [16].

The authors [17] give data similar to those provided by [16], but for three average soil moistures. Table 2 gives the results of the calculation of the model parameters as in 2.1.1, but separately for different humidity, and separately on the global data, regardless of humidity.

Table 2

\section{Results of the interpolation by the least-squares method (or least-squares fitting) for the experimental data from [17]}

\begin{tabular}{|c|r|l|r|r|c|}
\hline Soil moisture, $\boldsymbol{h}, \boldsymbol{\%}$ & \multicolumn{1}{c|}{$\boldsymbol{f G}, \mathbf{N}$} & $\boldsymbol{k}, \mathbf{N} \cdot \mathbf{m}^{-\mathbf{2}}$ & $\boldsymbol{\varepsilon} \mathbf{~} \mathbf{~ k} \cdot \mathbf{m}^{-\mathbf{3}}$ & Correlation & $\boldsymbol{R}^{\mathbf{2}}$ \\
\hline 16.1 & 2664.12 & 14557.751 & 9355.48 & 0.950 & 0.903 \\
\hline 22.0 & 2413.483 & 14576.056 & 9547.043 & 0.944 & 0.891 \\
\hline 25.4 & 2317.329 & 14109.408 & 8899.809 & 0.946 & 0.895 \\
\hline- & 2464.978 & 14414.405 & 9267.444 & 0.939 & 0.882 \\
\hline
\end{tabular}

All the model parameters have positive values, therefore, from this point of view (criterion $\mathrm{C} 2$ ), formula (1) passes this test. The coefficient of resistance to deformation of the soil $k$ takes values within the range allowed by all the reference works regarding this formula, [2], [4-8]. The coefficient of resistance, $\varepsilon$, that appears in the term dependent on the speed is higher (about four times higher) than the values indicated in the same literature.

The results of the test of Goriacikin's formula for the experimental data from [18] are given in Table 3. The experiments were carried out for three machines: mouldboard plough, disk plough and chisel plough, representative types for modern agricultural technologies. In order to be able to apply formula (1) for the disk plough and chisel plough, we calculated the working width equivalent so that the areas of the working bodies, designed on the normal plane to the forward direction, would be equivalent to that of a rectangle with the given working depth, and the working width calculated from the data found in [18].

Table 3

Results of the interpolation using the least-squares method for the experimental data from [18]

\begin{tabular}{|l|c|c|c|c|c|}
\hline \multicolumn{1}{|c|}{ Equipment } & $\boldsymbol{f G}, \mathbf{N}$ & $\boldsymbol{k}, \mathbf{N} \cdot \mathbf{m}^{-\mathbf{2}}$ & $\boldsymbol{\varepsilon}, \mathbf{k g} \cdot \mathbf{m}^{-\mathbf{3}}$ & Correlation & $\boldsymbol{R}^{\mathbf{2}}$ \\
\hline Mouldboard plough & 827.850 & 13780.634 & 15709.994 & 0.964 & 0.930 \\
\hline Disk plough & -1374.002 & 38661.002 & 14135.610 & 0.938 & 0.879 \\
\hline Chisel plough & 386.710 & 216181.811 & 97314.400 & 0.991 & 0.982 \\
\hline
\end{tabular}

It is observed that for the mouldboard plough and chisel plough, the model parameters are positive and the formula passes the test, whereas for the disk plough, the static term that depends on the friction is negative and the formula does not model the draft soil tillage force well in this case. Even though for the mouldboard plough and the chisel plough the test of positivity of the model parameters is passed, however, the parameter $\varepsilon$ has much higher values than those provided in [2] and, in general, in the literature. The term $f G$ also has values of up to an order lower than those used in the calculations in $[2 ; 5]$, etc. Obviously, even the ranges of values mentioned in the literature for the model parameters of formula (1) do not cover all the possible certain cases, often meeting on hard and dry soils values well over 100,000 Pa, for $k$, for example. The approximations made by Goriacikin's formula, for these experiences are of very good quality, as shown by the correlation and the determination index.

In [3], for machines for soil tillage in the United States, the formula is recommended: 


$$
F=\varphi\left(A+B v+C v^{2}\right) a b .
$$

Formula (3) depends on the speed, the rest of the zworking parameters being included in the polynomial coefficients of the speed (working width and depth, etc.). The model parameters are experimentally determined for certain equipment and listed. Using the same method as in the case of model (1) (which is based on the smallest squares method for identifying the parameters of the mathematical model), the model (3) is tested for draft tillage force.

For the beginning, the test results by the method of the smallest squares are presented for the modelling capacity of the experimental data from [16], using formula (3) and three other variants thereof. The values of the model parameters, for each case, as well as the correlation between the experimental values of the force and those calculated by interpolation, and the coefficient of determination, are given in Table 4.

Table 4

Values of the coefficients from formula (3) for the experimental data from [16], in four variants

\begin{tabular}{|c|c|c|c|c|c|}
\hline Formula & $\boldsymbol{A}, \mathbf{N}$ & $\mathbf{B}, \mathbf{~ k g} \cdot \mathbf{s}^{-\mathbf{1}}$ & $\mathbf{C}, \mathbf{k g} \cdot \mathbf{m}^{-\mathbf{1}}$ & Correlation & $\boldsymbol{R}^{\mathbf{2}}$ \\
\hline$F=A+B v+C v^{2}$ & 27173.368 & -3601.753 & 641.774 & 0.965 & 0.894 \\
\hline$F=A+B v$ & 19953.407 & 1349.077 & 0 & 0.982 & 0.915 \\
\hline$F=A+C v^{2}$ & 24622.618 & 0 & 3.337 & 0.955 & 0.857 \\
\hline$F=B v+C v^{2}$ & 0 & 79224.332 & -14084.607 & 0.051 & -46.897 \\
\hline
\end{tabular}

Regarding the criterion of positivity of the coefficients of the terms of the draft soil tillage force, it is observed that only the expressions containing the constant term and the first-degree term, respectively, the constant term and the second-degree term in the working speed, can be accepted. These two types of expressions are also found in the tables in [3] and [1]. As a further observation, it can be considered that the order of magnitude of the constant term is with a unit greater in general than the values given in [3], taking into account the maximum texture factor and the working width and depth. The situation is valid also for the coefficients of the terms of the first degree, respectively the second, for the formulas that pass the test of positivity of the coefficients. However, this observation must be made in each concrete case in the most precise working conditions. In addition, the small values of the correlation between the experimental data and the corresponding interpolated values, as well as the coefficient of determination, show that the approximation of the experimental data from [16] with formula (3) or one of its variants is not satisfactory. Variants of formulas of type (3) appear not only in [3] but also in other sources, for example [19;20]. In order to increase the performance of these formulas, testing should be done separately on data with the same working widths and depths, as well as the same soil type. We do not have such data. For this reason, the test of this type for formula (3) can be considered insignificant.

The results of the test of formula (3) for the experimental data given in [17] are summarized in Table 5, for the soil moisture value $16.1 \%$. For the other values of soil moisture, the corresponding tables can be found in [15].

Table 5

Values of the coefficients of formula (3) for the experimental data from [17], in four variants, for the soil moisture with the value of $16.1 \%$

\begin{tabular}{|c|c|c|c|c|c|}
\hline Formula & $\boldsymbol{A}, \mathbf{N}$ & $\mathbf{B}, \mathbf{~ k g} \cdot \mathbf{s}^{-\mathbf{1}}$ & $\mathbf{C , ~} \mathbf{k g} \cdot \mathbf{m}^{-\mathbf{1}}$ & Correlation & $\boldsymbol{R}^{\mathbf{2}}$ \\
\hline$F=A+B v+C v^{2}$ & 40848.575 & -2017635.845 & 24468.295 & 0.931 & 0.536 \\
\hline$F=A+B v$ & 23040.761 & 16885.319 & 0.000 & 0.933 & 0.548 \\
\hline$F=A+C v^{2}$ & 38085.593 & - & 145.677 & 0.828 & 0.333 \\
\hline$F=B v+C v^{2}$ & - & 819051.422 & -741515.524 & -0.286 & -249.578 \\
\hline
\end{tabular}

In this case, the lower capacity of the mathematical modelling of the experimental data for formula (3) compared to formula (1) is also observed.

Among the variants considered in the calculation for formula (3), the models that contain the constant term and the first-degree term in the working speed, respectively the constant term and the term of the second degree in the working speed, are physically validated. The other variants are 
physically rejected (criterion C1). The authors [17] consider that the most efficient formulas for modelling the draft soil tillage force are those that depend on the square of the working depth and the speed of work, or the square of the working depth and the square of the working speed. The working speed is detected as the main model parameter in most of the works that deal with the traction force modelling for agricultural machines intended for soil works, for example [3; 21], etc. However, in comparison to the static terms (which do not contain the working speed parameter), the terms that contain the working speed are small, because the working speeds of the machines intended for soil work are low. For this reason, especially for large, heavy machinery, components that contain working speed, are or may be neglected in relation to static components $[5 ; 22]$.

In [21], the dependence of the traction force on the soil density, soil moisture, depth and the working width is also considered. Soil density appears as a major component of soil modelling in formula (1), by the parameter $\varepsilon$, which is clearly specified in [2]. Moreover, it is good to consider the unit of density measurement as the unit of measure of the parameter $\varepsilon$ in the Goriacikin model, (1). The authors' research [21] shows that the traction force decreases with humidity, and the increase in the working speed leads to an increase in the traction force. In [13], the traction force is modelled using parameters similar to [2], in addition being highlighted the angles that describe the geometry of the ploughing instruments. Formulas of type (3) are used in [13] for elementary modelling of the specific traction for mouldboard ploughs. Formulas of type (3) are used, without the term in the first power of the working speed being specified, numerically exact, model parameters, depending on the type of soil.

Also, in the case of formula (3), a study can be made of the dependence of the soil moisture, of the model parameters, as in the case of formula (1).

Finally, the results of the test of formula (3) for the experimental data from [18] are presented. For the experimental data presented in [18], we tested the model (3) together with three variants of it for each of the machines that were experimented with: mouldboard plough, disk plough and chisel plough. The results presented in Table 6 are given only for the mouldboard plough experimental data. For the other types of soil tillage machines the results can be found in [15].

Table 6

Values of the coefficients of formula (3) for the experimental data from [18], in four variants, for the mouldboard plough

\begin{tabular}{|c|c|c|c|c|c|}
\hline Formula & $\boldsymbol{A}, \mathbf{N}$ & $\mathbf{B}, \mathbf{k g} \cdot \mathbf{s}^{-1}$ & $\mathbf{C}, \mathbf{k g} \cdot \mathbf{m}^{-1}$ & Correlation & $\boldsymbol{R}^{\mathbf{2}}$ \\
\hline$F=A+B v+C v^{2}$ & 55169.429 & -57130.928 & 41371.447 & 0.961 & 0.891 \\
\hline$F=A+B v$ & 10449.652 & 33886.257 & 0.000 & 0.938 & 0.846 \\
\hline$F=A+C v^{2}$ & 47060.102 & 0.000 & 496.191 & 0.625 & 0.345 \\
\hline$F=B v+C v^{2}$ & 0.000 & 762904.564 & -549091.306 & -0.644 & -128.061 \\
\hline
\end{tabular}

It can be seen from the result in Table 6 and from the tables for the other two variants in [15] that for all three machines used in the experiments, which results are given in [18], only two variants, the same, can be taken into account, the model parameters being positive: the variant containing the constant term and the term of the first degree in the speed, respectively the variant that contains the constant term and the term of the second degree in the working speed. In general, the best option is the second, which is formula (1) for a particular case. The quality of the approximation is lower in formula (3) than in the case of formula (1).

Other results and data are presented in [15], including tests for laboratory experiments in [23].

\section{Conclusions}

Generally, in this article mathematical models of the draft soil tillage force for agricultural equipment for soil works are given, which can be grouped into four categories:

- Goriacikin type formulas;

- formulas dependent by the second degree of the working speed, of type ASAE;

- formulas that contain detailed geometrical characteristics of the working bodies and are based on soil mechanics considerations;

- formulas that come from the statistical modelling of the experimental results. 
The presence of the constant term in the draft soil tillage force formula, whatever it may be, poses a problem of physical meaning, when trying to use this force in a dynamic regime. The constant term has the meaning of a component that does not cease with the movement and most of the times must be supplemented with special factors that take into account the movement (non-speed) or rest. The terms that contain the working speed of the unit can be of degree one or two in the working speed. These terms are less visible for small values of speed (below $3 \mathrm{~m} \cdot \mathrm{s}^{-1}$ ), and nonlinearity is still less visible.

The use of such a large number of variants of a physical law for a quite well-defined physical process can leave the impression of heterogeneity of the descriptions of the phenomenon, created so that various authors and users apply different particular formulas for evaluating of the soil tillage draft force. The impression of heterogeneity is only apparent, however, as a summary analysis will show that the mathematical models used for the evaluation of the traction force in soil processing are convergent to one common final form. We have to observe only that many of the parameters of each variant are only apparently constant only in the given experimental conditions and, basically, they depend on other parameters that appear in other formulas. Otherwise, we are rather in a situation, where slightly different languages are spoken and between which the correct translation is necessary. Nor do we deny the need to jointly complete a list as comprehensive with the model parameters of the phenomenon.

As a general conclusion, the physical law of the draft soil tillage force is complex and cannot be summed up to a two- or three-parameter dependence, such as the simple stated laws of gravity, Hooke's law, Ohm's law, etc. Nor are these laws as simple as in the forms in the textbooks, but these simple forms have a wide scope. The physical law of the draft soil tillage force cannot work satisfactorily for very simplified forms.

As all the laws of physics are approximate and change in detail at certain intervals to increase accuracy, it means that, relative to the absolute truth, they are all false (or maybe just incomplete). The law of the draft soil tillage force for soil processing machines is no exception.

\section{Acknowledgements}

This work was supported by a grant of the Romanian Research and Innovation Ministry (RRIM), through Programme 1 - Development of the national research-development system, subprogram 1.2 Institutional performance - Projects for financing excellence in RDI, contract No. 16PFE, and was done by "NUCLEU" Programme, developed with the support of the RRIM, project PN 19100102.

\section{References}

[1] Cardei P. General structure of tillage draft force. Consequences in experimental and applicative researches, preprint, DOI: 10.13140/RG.2.2.31933.56808, 2018.

[2] Letosnev M.N., Masini Agricole, Ministerul Agriculturii si Silviculturii, Editura Agro-Silvica de Stat (Agricultural Machines, Ministry of Agriculture and Forestry, State Agro-Forestry Publishing House), Bucharest, 1959. (In Romanian).

[3] American Society of Agricultural Engineers [ASAE]. 2003a. "D497.4 Agricultural machinery management data." p. 373-380. In: ASAE. ASAE standards 2003.

[4] Toma D., Neagu T., Florescu I., Lepsi S., Tractoare agricole, Editura Didactica si Pedagogica, (Agricultural tractors, Didactic and Pedagogical Publishing House), Bucharest, 1978.. (In Romanian).

[5] Sandru A., Popescu S., Cristea I., Neculaiasa V., Exploatarea utilajelor agricole, Editura Didactica si Pedagogica, (Exploitation of agricultural equipment, Didactic and Pedagogical Publishing House), Bucharest, 1983. (In Romanian).

[6] Tecusan N., Ionescu E., Tractoare si automobile, Editura Didactica si Pedagogica (Tractors and automobile, Didactic and Pedagogical Publishing House), Bucharest, 1982. (In Romanian).

[7] Scripnic V., Babiciu P., Masini agricole, Editura Ceres (Agricultural machines, Ceres Publishing House), Bucharest, 1979. (In Romanian).

[8] Sandru A., Badescu M., Sandru L., Reducerea consumului de energie prin folosirea rationala a agregatelor agricole, Editura Scrisul Romanesc, (Reduction of energy consumption through the rational use of the agricultural aggregates, Romanian Writing Publishing House), Craiova, 1982. (In Romanian). 
[9] Musil J., Cervinka J., Measuring of pulling resistance in machinery with passive working parts, Research. Agricultural Engineering, 53, (2), 2007, pp. 47-53.

[10] Vilde A., Dynamics of the soil tillage machine operating parts and their elements, Proceedings LLU, 1 (295), 1999, pp. 36-44.

[11] Scripnic V., Babiciu P., Masini agricole, Editura Ceres (Agricultural machines, Ceres Publishing House), Bucharest, 1979. (In Romanian).

[12] McKyes E., Soil Cutting and Tillage, Elsevier, 1985.

[13] Srivastava A.,K., Goering C., E., Rohrbach R., P., Buckmaster D., R., Engineering Principles of Agricultural Machines, 2nd Edition, ASABE, 2006.

[14]Larson L., W., Predicting draft forces using model moldboard plows in agricultural soils, A Dissertation Submitted to the Graduate Faculty in Partial Fulfillment of The Requirements for the Degree of DOCTOR OF PHILOSOPHY, 1964.

[15] Cardei P., Tests for physical laws of the draft force generated in the tillage operations, Preprint RG, DOI: 10.13140/RG.2.2.16582.01607, 2019.

[16] Akbarnia A., Mohammadi A., Farhani F., Alimardani R., Simulation of draft force of winged share tillage tool using artificial neural network model, Agric Eng Int: CIGR Journal, 16(4), 2014, pp. 57-65.

[17] Ranjbar I., Rashidi M., Najjarzadeh I., Niazkhani A., Niyazadeh M., Modeling of Moldboard Plow Draft Force Based on Tillage Depth and Operation Speed, Middle-East Journal of Scientific Research 17 (7), 2013, pp. 891-897.

[18] Naderloo L., Alimadani R., Akram A., Javadikia P., Khanghah H., Z., Tillage depth and forward speed effects on draft of three primary tillage implements in clay loam soil, Journal of Food, Agriculture \& Environment Vol.7 (3\&4), 2009, pp. 382-385.

[19] Jyoti B., Reddy K.,V.,S,R., Sawant C., P., Pandirwar A., P., Potdar R., R., Randhe R.,D., Predicting Draft Requirement of Tillage Implements Using Pull Type Load Cell in Southern Region of Andhra Pradesh, India, International Journal of Current Microbiology and Applied Sciences ISSN: 2319-7706 Volume 9 Number 01, 2019.

[20]Zadeh S.,R., A., Kushwaha R., L., Development of a Tillage Energy Model Using a Simple Tool, CSBE/SCGAB 2006 Annual Conference Edmonton Alberta July 16-19, 2006.

[21] Nkakini S., O., Draught force requirements of a disc plough at various tractor forward speeds in loamy sand soil, during ploughing, International Journal of Advanced Research in Engineering and Technology, vol. 6, Issue 7, 2015, pp. 52-68.

[22] Krasnicenko A., V., Manualul constructorului de masini agricole, Editura Tehnica (The manual of the agricultural machine manufacturer, Technical Publishing House, Bucharest 1964. Vol. 2. (In Romanian).

[23]Fechete-Tutunaru L.V., Gaspar F., Gyorgy Z., Soil-tool interaction of a simple tillage tool in sand, E3S Web of Conferences 85, 08007, EENVIRO 2018, 2019. 